$\begin{array}{ll} & \text { Etnográfica } \\ \text { etnográfica } & \text { Revista do Centro em Rede de Investigação em }\end{array}$

Antropologia

vol. $18(2) \mid 2014$

Vol. $18(2)$

\title{
Sentidos da antropologia em Portugal na década de
} 1970

Meanings of anthropology in Portugal in the 1970s

\section{Jorge Freitas Branco}

\section{(2) OpenEdition}

Journals

Edição electrónica

URL: https://journals.openedition.org/etnografica/3732

DOI: 10.4000/etnografica.3732

ISSN: 2182-2891

\section{Editora}

Centro em Rede de Investigação em Antropologia

\section{Edição impressa}

Data de publição: 1 junho 2014

Paginação: 365-378

ISSN: 0873-6561

\section{Refêrencia eletrónica}

Jorge Freitas Branco, «Sentidos da antropologia em Portugal na década de 1970», Etnográfica [Online], vol. 18 (2) | 2014, posto online no dia 09 julho 2014, consultado o 11 fevereiro 2022. URL: http:// journals.openedition.org/etnografica/3732 ; DOI: https://doi.org/10.4000/etnografica.3732

\section{(c) (1) (8)}

Etnográfica is licensed under a Creative Commons Attribution-NonCommercial 4.0 International License. 


\section{Sentidos da antropologia em Portugal na década de 1970}

\section{Jorge Freitas Branco}

O presente texto situa acontecimentos e processos ocorridos nos anos 70, relevantes para o percurso da antropologia em Portugal. Assenta em informação disponível e outra presenciada. Não estando, na altura, ainda estabilizada a sua institucionalização disciplinar, defende-se que o período foi de cumprimento de um luto intelectual provocado pelo choque da emancipação colonial e pela mudança de paradigma científico (fim da busca de harmonia ou igualitarismo, enfoque no conflito ou desigualdade).

PALAVRAS-CHAVE: Portugal, antropologia social, antropologia cultural, anos 1970, luto, alteração de paradigma.

Meanings of anthropology in Portugal in the 1970s - This article situates events and processes that occurred during the 1970s, relevant for the development of anthropology in Portugal. It is based on both information already available as well as lived experience. Because at the time anthropology was not yet an entirely institutionalized discipline, we propose that this period constituted a phase of intellectual mourning provoked both by the shock of colonial emancipation and by a shifting scientific paradigm (abandonment of the search for harmony or egalitarianism, in favor of new focuses on conflict and inequality).

KEYWORDS: Portugal, social anthropology, cultural anthropology, 1970s, mourning, changing paradigm.

BRANCO, Jorge Freitas (jorge.branco@iscte.pt) - Centro em Rede de Investigação em Antropologia (CRIA), ISCTE - Instituto Universitário de Lisboa (ISCTE-IUL), Portugal. 


\section{UM BATISMO INFORMAL SERVE DE INTRODUÇÃO}

Em setembro de 1976, realizou-se em Lisboa a 28. ${ }^{a}$ Assembleia Geral da Associação Internacional de Críticos de Arte (AICA). O programa de atividades incluiu a exposição "Modernismo e Arte Negro-Africana", patente ao público no Museu de Etnologia. Um quadro de Picasso, emprestado pelo Museu Hermitage, da então Leninegrado, disputava sem esforço protagonismo aos artefactos africanos. Isso acontecia por várias razões. A temática da exposição remetia para a África ao sul do Sara, assentava numa abordagem ensaiada do ponto de vista artístico e realizava-se num museu que não era tido como de arte. Sugestionava-se no visitante o confronto entre correntes da arte ocidental com o mundo dito primitivo (cf. Lima 1976). Peças etnográficas estavam encenadas como objetos artísticos. A estes fatores, somavam-se outros. Ao público desvendavam-se mais coisas novas e inusitadas. A exibição do Picasso implicava segurança policial especial. Era também facto inédito para aquele tempo, em Portugal, a origem do empréstimo. Comprovava as relações políticas internacionais normalizadas recentemente. Por fim, o local visitado era novo. Ficava no bairro do Restelo, em frente ao edifício que até ao 25 de Abril acolhera o Ministério do Ultramar e que, depois de um interregno como Ministério da Coordenação Interterritorial - durante as negociações para a descolonização -, passou a um efémero da Cooperação, antes de transitar para a tutela do Ministério da Defesa. Mas a referência mais popular seria por certo o vizinho estádio do clube de futebol Os Belenenses. Era um museu acabado de construir, concebido de raiz para acolher, manter e divulgar coleções etnográficas, e que esperava inauguração. Designava-se Museu de Etnologia do Ultramar; no entanto, o catálogo editado já só referia Museu de Etnologia (SEC 1976).

Concebido durante a guerra colonial, em que se mantinham três frentes de combate simultâneas (Angola, Guiné, Moçambique), agora a situação mudara, porque se haviam calado as armas e as colónias acediam em fila à independência. O rebatismo do museu não passava ainda de um ato espontâneo, informal. Só em 1985 se verificaria a sua abertura oficial ao público. E tornava-se só então efetiva a supressão do atributo geográfico na designação institucional.

\section{SOMBRAS PROJETADAS}

A queda do regime salazarista ocorrida em 1974 criou condições novas na sociedade portuguesa: o novo poder era militar e incluía no seu programa político os 3D: democratização, descolonização, desenvolvimento. O país caminhava para profundas transformações. No que respeita a antropologia, desenham-se algumas das sombras do passado.

Em primeiro lugar, a figura de António Jorge Dias (1907-1973), recentemente falecido. Foi o antropólogo que mais influenciou a disciplina nas décadas anteriores. Em 1947, na cidade do Porto, liderou um Centro de Estudos de 
Etnologia Peninsular, onde congregou uma equipa que se profissionalizaria, dedicada à etnografia portuguesa (na altura acrescentava-se metropolitana). Era formada por Ernesto Veiga de Oliveira (1910-1990), Fernando Galhano (1904-1995), Benjamim Pereira (1928-) e, durante um período, Margot Dias (1908-2001). Na década seguinte António Jorge Dias interessa-se pelo domínio africano, será nomeado professor do então Instituto Superior de Ciências Sociais e Política Ultramarina (ISCSPU) e, no âmbito da Missão de Estudo das Minorias Étnicas do Ultramar, lança o seu projeto dedicado aos Maconde, no Norte de Moçambique (Gallo 1988; R. Pereira 2006; West 2004). Em 1965, ao ser criado no papel o Museu de Etnologia do Ultramar, será nomeado seu primeiro diretor. Nesse contexto também se funda o Centro de Estudos de Antropologia Cultural (CEAC), que deverá servir de estrutura de investigação em apoio ao museu e que igualmente dirige (cf. M. M.C. Pereira 2005). Aqui se juntaram ao longo do tempo, e em geometria variável, investigadores e colaboradores, alguns com experiência adquirida anos a fio na administração colonial. Jorge Dias faleceu sem conhecer o edifício do museu terminado.

O grupo da etnografia portuguesa, entretanto liderado por Ernesto Veiga de Oliveira, transferira-se em 1967 para Lisboa e partilhava as instalações onde funcionava a título provisório o museu, pertencentes à Junta de Investigações do Ultramar (na rua Jau, Lisboa). Coabitavam aí duas entidades, com inserções institucionais distintas (Ministério da Educação para a etnografia portuguesa e Ministério do Ultramar para as de origem exótica, mais o museu). Terá funcionado uma colaboração transversal informal na manutenção das coleções entretanto constituídas (E. V. Oliveira 1968).

Com o fim das colónias, a respetiva política de ciência perdia razão de ser. A reformulação demorou, dando origem ao Instituto de Investigação Científica Tropical (IICT), criado em finais de 1979. Absorvia os recursos de ciência herdados do tempo colonial. Em consequência, o Museu de Etnologia foi integrado no IICT e desapareceu o CEAC, substituído pelo Centro de Antropologia Cultural e Social (CACS).

Durante a década de 1970, a principal instituição especializada em antropologia do país não se assumia nessa função, amarrada à reestruturação pós-colonial e no seu seio dividida entre dois setores que não conseguiam convergir: o domínio doméstico e o exótico. A mencionada exposição de 1976, integrada no programa do congresso da AICA, cujo tema, "Black African Art and Modern Art: Reciprocal Relations", foi uma tentativa feita de dentro da instituição chamando a atenção governamental para a necessidade de definir um destino a dar àquela estrutura museológica. Assim foi entendida a iniciativa pela imprensa ${ }^{1}$

l Vejam-se o matutino lisboeta Diário de Notícias de 7 e 8 de setembro de 1976, páginas 4 e 7, respetivamente, e ainda o vespertino Diário de Lisboa, de 6 de setembro de 1976, página 7 (artigos não assinados). 
e por especialistas (Sousa 1976). Mas, finda a exposição, as portas fecharam-se sem apelo, nem agravo.

Nas universidades de Coimbra e do Porto, a antropologia confinava-se a uma atividade museológica (manutenção das coleções, seu uso demonstrativo no ensino), sem incidência pública (ausência de exposições), enquadrada prioritariamente pela explicação biológica e genética (prestação de serviços graças a um posto antropométrico) e menos pela abordagem cultural.

\section{INPUTS}

Até ao 25 de Abril o ensino de matérias antropológicas (na abordagem cultural) resumia-se a disciplinas optativas nas faculdades de letras, previstas na formação de geógrafos. E no já mencionado ISCSPU existia desde 1968 um Curso Complementar de Ciências Antropológicas e Etnológicas, com nível de licenciatura. Matérias antropológicas eram ministradas desde muito antes nesta instituição na preparação de administradores coloniais (exemplo de "Instituições Indígenas”, lecionada por António Jorge Dias). Logo em setembro de 1974, o curso foi reformulado, contrataram-se novos docentes e afastaram-se ("sanearam-se") alguns dos antigos, considerados ideologicamente ligados ao regime deposto e, do ponto de vista científico, tidos por desatualizados. Espraiava-se a vaga europeia da década de 1960, embebida nas correntes do estruturalismo ou marxismo. Os novos docentes eram jovens regressados do estrangeiro (França, Bélgica), onde tinham estudado ou ainda estavam a preparar o doutoramento (Joaquim Segurado, José Carlos Gomes da Silva, José Fialho Feliciano, Maria Olímpia Campagnolo, Pedro Castro Henriques, Rui Rodrigues, entre outros). A maior parte deles tinha partido para não prestar serviço militar na guerra colonial. Vivia-se em pleno uma crise revolucionária. Menos na antropologia, do que noutras ciências sociais (sociologia, economia), jovens de outras proveniências (fugidos a outras ditaduras: brasileiros, chilenos) também se sentiram atraídos pela situação portuguesa e deram o seu contributo temporário ou definitivo para a estruturação do ensino das ciências da sociedade.

A liberdade de expressão e de opinião, o questionamento das instituições, a instauração de mecanismos de participação democrática, eis alguns dos fatores que incrementaram a procura dos estudos sociais em geral e do conhecimento do passado. Institucionalizam-se as ciências sociais nos diversos ramos, entre eles a antropologia, cujo primeiro curso de licenciatura completo (quatro anos) é criado na Universidade Nova de Lisboa, em 1978 (MEIC 1978; ME 1979). A antropologia passava a dispor de condições de ensino e da sua reprodução (Cordeiro e Afonso 2003). A função de controlo da reprodutibilidade deste saber específico não podia ser assumida pelo museu, o que viria a ditar a sua subalternização dentro da comunidade antropológica em gestação. Em paralelo, verificava-se que a antropologia académica emergente acabava 
de se posicionar numa faculdade de ciências sociais (embora também com as humanidades por arrastamento duma dissidência). A antropologia não foi acolhida pelas faculdades de letras existentes nas universidades antigas. Pese a relatividade da classificação, as primeiras tinham um potencial inovador que não se entrevia nas últimas.

Durante a década preponderaram ainda os conteúdos ligados à tradição intelectual francófona, com uma tendência crescente para o uso de bibliografia anglo-saxónica, acedida em inglês. Consumou-se o triunfo da fotocópia (quase sempre Xerox), ainda que elas saíssem húmidas da máquina, com um odor próprio e não resistissem demasiado ao tempo. Não havia autosserviço. Encomendavam-se sempre a um/a operador/a, o que constituía um negócio rendoso. O estudante português não estava afeiçoado à manipulação de teclados, a não ser alguns, por se dedicarem a instrumentos musicais. Os trabalhos eram mandados passar à máquina (manuais, dado o elevado custo das elétricas), o que fazia da datilografia uma atividade lucrativa, garantindo o sustento de muita gente.

Nesta década, Portugal era um país que dispunha de horário de abertura. As fronteiras fechavam à noite. A exceção acontecia durante o mês de agosto, na maior fronteira terrestre, a de Vilar Formoso. Em vez de encerrar entre a uma e as seis horas da manhã, ficava aberta sem interrupção, por causa dos emigrantes que vinham de "vacanças". Mas o país tinha outras fronteiras com traçado diferente. Para as camadas urbanas letradas, o interior quase constituía uma terra incógnita. Tal desconhecimento reforçava-se com o esvaziamento demográfico que desde a década anterior acontecia. A população migrava em massa para o litoral e para além-Pirenéus. O Plano Trabalho e Cultura (PTC), levado a efeito no verão de 1975 (Branco e Oliveira 1993; L. T. Oliveira 2004) ou as Campanhas de Dinamização Cultural e Ação Cívica, desencadeadas pelos militares revolucionários (Almeida 2009), traduzem um propósito voluntarista de ir em demanda dessa face ocultada do país. Já José Cutileiro colocara na abertura da sua monografia sobre uma vila alentejana (Cutileiro 1971, versão portuguesa de 1977) a frase do poeta Alexandre O'Neill: "Portugal, questão que eu tenho comigo".

Nada disto tem a ver diretamente com a antropologia em Portugal nos anos 1970, mas revela um estado de espírito existente em grupos intelectuais, que os tempos revolucionários intensificavam. Traduzia um mal-estar criado pela consciência do atraso do país, económico (industrialização periférica), político (regime autoritário acabado de colapsar) e social (baixos índices de prosperidade da população). A este facto acrescem as limitações financeiras e logísticas para fazer terreno em paragens longínquas, o que explica a motivação dos estudantes de antropologia, tanto no ISCSP (até à suspensão da atividade letiva por ordem governamental, mantida entre finais de 1976 e 1980), como depois na Universidade Nova de Lisboa, canalizada para que se aplicassem no terreno português os seus conhecimentos e as suas capacidades de operacionalizar 
pesquisa. Dois acontecimentos paralelos à universidade tiveram repercussão no contingente reduzido de estudantes, professores e apreciadores de assuntos antropológicos. A estreia comercial do filme Trás-os-Montes, realizado por António Reis e Margarida Cordeiro, ${ }^{2}$ assim como, nesse mesmo ano, uma panorâmica da obra de Jean Rouch (1917-2004), realizada na Fundação Calouste Gulbenkian (CPR 1976).

\section{DELITO DE MOCIDADE}

Fiz parte da última leva de licenciados em antropologia (a designação oficial era Ciências Antropológicas e Etnológicas) do ISCSP - antiga Escola Superior Colonial, em 1962 integrada na Universidade Técnica de Lisboa como ISCSPU. Como finalistas fomos surpreendidos pelo encerramento - já referido - feito por ordem ministerial. Durante os estudos debatera-se apaixonadamente o papel do antropólogo na sociedade, sublinhara-se a necessidade de suscitar a procura do seu saber. Mas este era um problema comum aos outros ramos das ciências sociais em processo de consolidação universitária. A grande saída para os licenciados em muitas áreas era a docência no ensino básico e secundário, dada a explosão da população escolar que se verificava. Findo o colonialismo e a guerra colonial, o país voltava-se para dentro e, desde logo, assumia políticas expansivas e abrangentes na educação e na saúde.

Regressei à terra (adotiva) procurando um início de vida, despido da ilusão de aproveitar a formação obtida. Trabalhei no turismo. A implantação de uma administração pública regional como consequência da autonomia para as regiões insulares prevista na constituição de 1976 e implementada a partir de 1977 pelo recém-instalado governo regional madeirense foi uma oportunidade para muitos jovens recém-licenciados. Fui contratado, em 1978, para a Direção Regional de Assuntos Culturais (DRAC), que estava a ser criada. O que pouco antes me parecia irrealista, acontecia. A minha formação em antropologia fora um critério de peso. Achei-me rapidamente envolvido numa atividade abrangendo a programação, o planeamento e a execução de projetos culturais. Esperava-se de mim um contributo em sintonia com o período político vivido: a realidade criada pela autonomia. Importava detetar e valorizar os componentes definidores de identidade regional. A necessidade de diferenciação do exterior sentia-se no dia a dia, manifestando-se com maior ou menor veemência nas relações políticas entre os governos regional e nacional. Para reforço das reivindicações políticas forjavam-se argumentos de índole identitária.

Absorvido nesta experiência, lembrei-me de ter lido muito antes, algures num texto de António Jorge Dias, que, em finais dos anos 40, se lhe tinha 
deparado uma situação similar à minha: devia definir um plano de trabalho que suscitasse aceitação e fosse viável concretizar. Nessa altura, para Jorge Dias, pairava a sombra e o legado de José Leite de Vasconcelos (1858-1941), sustentados numa rede estabelecida à escala nacional e composta por apaixonados por escavações e achados arqueológicos, especulando sobre símbolos e sentidos em tempos remotos. Por isso Jorge Dias se virara para a cultura material, protagonizando uma viragem centrada na recolha de material no presente e em uso: um terreno com gente e dela dependendo. Neste contexto nasceu o projeto do Atlas Etnográfico de Portugal, corria o ano de 1947. Esta mudança de atitude permitia alinhar a pesquisa com iniciativas equivalentes então a decorrer em muitos países europeus (elemento comparativo).

Cheguei a uma conclusão semelhante, mas o artigo de António Jorge Dias só me veio à memória no fim da minha reflexão. Era recente a publicação da Alfaia Agrícola Portuguesa (Oliveira, Galhano e Pereira 1976), a súmula do projeto do atlas etnográfico. Definir um tema no âmbito da cultura material, aplicado à Madeira, implicava começar de igual modo pela utensilagem agrícola. Também neste caso se evitariam as pequenas polémicas, discussões e impressões especulativas em torno da identidade regional ou em processo de regionalização, a propósito de música, dança, festividades ou gastronomia.

Recordava ainda as considerações que ouvira no Museu de Etnologia (continuava fechado ao público, mas era frequentado por um grupo mais ou menos restrito de interessados e de curiosos viciados naquelas causas). Comparavam-se as duas regiões insulares: enquanto dos Açores se afirmava possuírem uma etnografia rica, da Madeira dizia-se ser pobre. E passeávamos pelas reservas recheadas de alfaias agrícolas. Grande variedade de cada implemento caracterizava a situação açoriana, a Madeira pontuava pelo cariz uniforme dos equipamentos recolhidos. Não sei se isto terá ferido o meu sentimento insular, mas achei que isto não podia ser assim: etnografias ricas e etnografias pobres. Como se definem? Como se elabora a escala? Que significado podem ter os valores apurados? Naquela altura não sabia como argumentar. Mantinha-me num silêncio deferente, que não significava concordância.

Fui construindo um plano de trabalho, tendo por meta final a criação de um museu etnográfico da Madeira. Seria uma estrutura vocacionada para encenar as representações identitárias. Havia que programar recolhas, a fim de constituir coleções. Optei por começar pelo levantamento da alfaia agrícola à escala do arquipélago, servindo posteriormente de leitmotiv para um discurso expositivo. Era minha intenção identificar semelhanças e diferenças entre as duas ilhas habitadas do arquipélago. E, a partir da comparação, talvez fosse possível construir argumentação sobre o tal escalonamento das etnografias...

Trabalhei o terreno da Madeira (cf. Branco 1989) e de Porto Santo durante quase dois anos, aumentando a coleção de alfaias agrícolas, obtidas quase sempre por compra. Em agosto de 1980, em jeito de relatório sobre a atividade 
desenvolvida, organizou-se a exposição "Alfaia Agrícola Insular", montada numa tenda insuflável de grandes dimensões, colocada durante dois meses numa zona popular do Funchal (Campo Almirante Reis). ${ }^{3}$

O Museu Etnográfico da Madeira, situado na Ribeira Brava, foi inaugurado em 1996 (Matos 1999; Gouveia 2009). Depreende-se que a identidade madeirense, forjada no processo autonómico, se cimentou por outros caminhos.

\section{PORTUGAL COMO TERRENO}

Na corrente mediterranista inaugurada por Julian Pitt-Rivers (1919-2001) nos anos 50, com a monografia sobre Alcalá de la Sierra, uma aldeia da Andaluzia (The People of the Sierra, 1954) ${ }^{4}$ Portugal é parente pobre, numa família onde a Itália, a Espanha e depois a Grécia são os membros com maior presença. A obra de síntese elaborada por John Davis (1977) - ele próprio com trabalho de campo feito em Itália e na Líbia - refere Portugal baseando-se na obra de José Cutileiro (1971), então ainda recente. Ao longo da década aqui discutida, o território continental e insular português foi destino escolhido por uma série de jovens antropólogos/as que procuravam temas e lugares com vista à elaboração de teses de doutoramento. A respetiva listagem não pretende ser exaustiva, porque de alguns se perdeu o rasto. Constata-se a presença maioritária de estrangeiros. A ordenação cronológica proporciona o seguinte panorama.

Jeanne B. Purcell (1938-1984) dedicou-se ao romanceiro de tradição oral; era norte-americana e, entre 1969 e 1970, faz recolhas intensivas nos Açores, na Madeira e no continente. Embora não se trate de uma antropóloga, a sua postura perante o terreno permite colocar o seu domínio disciplinar como equiparável à disciplina que nos interessa. Apresentará o seu doutoramento na Universidade da Califórnia Los Angeles (UCLA), em 1976.

Fortunata Piselli (1942-) é uma socióloga italiana, na altura ligada à Universidade da Calábria. Interessou-se pela população camponesa dos arredores de Coimbra desde os anos 60. Entre 1971 e 1973 está novamente no terreno, fazendo uma série de entrevistas aprofundadas. Interrompe a pesquisa e deverá

3 Em 1984, defendi a minha tese de doutoramento na Universidade de Mainz, que teve versão posterior em português, na coleção "Portugal de Perto" da editora Dom Quixote (Branco 1987 [1984]). Propus uma visão alternativa da sistematização da cultura material rural elaborada pelo grupo em torno de Ernesto Veiga de Oliveira, na senda do Atlas. Centrei-me no papel do equipamento material na transformação da paisagem, ou seja, no grupo social e não no indivíduo. Preocupei-me em realçar a dinâmica social na gestão dos recursos ecológicos. Nesta perspetiva, as etnografias não são ricas, nem pobres. O equipamento disponível numa determinada época depende das forças sociais que se manifestam: aí há lugar para inovação, tradição, resistência, numa conjugação de interesses imprevisível. Em finais de 1983, deixei o Funchal e comecei uma experiência no ensino universitário (no então ISCTE, atual Instituto Universitário de Lisboa).

4 Disponível em < http://ia600202.us.archive.org/7/items/peopleofthesierr00191 l mbp/peopleofthe sierr00191 I mbp.pdf > (última consulta em maio de 2014). 
regressar depois do 25 de Abril, em 1980, preocupando-se com os processos de mudança ocorridos durante a década no seguimento da revolução. Está ligada ao catolicismo social e mantém contacto com Manuel L. Rodrigues de Areia (1937-), então responsável pelo Museu Antropológico da Universidade de Coimbra.

Moisés Espírito Santo (1938-) é um português que elaborou um desenvolvido relatório final de curso em Sociologia Rural na Ecole des Hautes Etudes en Sciences Sociales, em Paris. Faz trabalho de campo entre 1973 e 1976 em Reguengo do Fetal, próximo de Batalha, no centro do país, sua terra natal. Trabalha à maneira de etnólogo, conforme assume. Vê na freguesia como entidade administrativa territorial a essência da comunidade rural portuguesa. Vive e descreve as transformações desencadeadas pelo 25 de Abril.

Joaquim Pais de Brito (1945-), que estudara etnologia em Paris, regressa com o 25 de Abril a Portugal, nesse mesmo mês visita a aldeia de Rio de Onor, em Trás-os-Montes e decide passar uma temporada em 1976 nesse local, após ter obtido uma bolsa da Fundação Calouste Gulbenkian. Conforme afirma, pretendia viver uma experiência de estranhamento. Conhecia em pormenor a monografia de António Jorge Dias sobre a aldeia publicada em 1953, versando sobre estruturas sociais de tipo comunitário. ${ }^{5}$

Brian Juan O’Neill (1950-), norte-americano, estuda antropologia social na Universidade de Londres. Depois duma experiência na Galiza e com vista à sua tese de doutoramento, estabelece-se em Seixas, Trás-os-Montes, por 18 meses, de 1976 a 1977. O seu olhar centra-se nos mecanismos sociais geradores de desigualdade (propriedade, herança, casamento, bastardia), em contradição com o discurso ouvido da boca dos habitantes da aldeia.

Também nesta década a norte-americana Denise Lawrence faz terreno no Sul do país, nos arredores de Évora. A sua tese de doutoramento, intitulada Festa: Cooperation in Rural Southern Portugal, foi defendida em 1979 na Universidade da Califórnia Riverside.

Três antropólogas dedicaram-se à emigração feminina lusa para França. Colette Callier-Boisvert (1938-), francesa, conhece o terreno português - Soajo, no Alto Minho - desde 1962, e enveredava agora pelo tema do êxodo rural visto na sociedade de acolhimento (Callier-Boisvert 1999). Em paralelo, uma norte-americana de origem canadiana, Caroline Bretell, estudou o mesmo assunto, dando origem à sua tese de doutoramento Hope and Nostalgia: The Migration of Portuguese Women to Paris, apresentada na Universidade de Brown, em 1978. Falta referir uma pioneira na temática das migrações, com terreno - multissituado avant la lettre - feito na origem (região de Viseu) e no destino (França): Maria Beatriz Rocha-Trindade (1938-), que em finais de 60

5 Ver < http://cpdoc.fgv.br/cientistassociais/joaquimbrito > , 5. ${ }^{\circ}$ bloco (última consulta em maio de 2014). 
estuda portugueses nos arredores de Paris, apresentando a sua tese em 1970, na Sorbonne, intitulada Immigrés portugais: Observation psycho-sociologique d'un groupe de Portugais dans la banlieue parisienne (Orsay).

Anne Caufriez, é belga, recolheu a partir de 1978 e até 1983, em sucessivas missões etnomusicológicas, material para o estudo comparado da balada ibérica (romanceiro), que se destinaria ao seu doutoramento em Paris. Na altura concentrou-se no Nordeste português (região mirandesa).

João de Pina-Cabral (1954-), doutorando em Oxford, faz o seu trabalho de campo no Alto Minho, em 1979-80, centrado nos aspetos simbólicos da morte, com vista à sua tese. ${ }^{6}$

Verificamos a existência de uma série de pesquisas de terreno dedicadas ao país e à diáspora, envolvendo antropólogos/as nativos e estrangeiros/as. Os materiais recolhidos reverteram para teses defendidas em universidades estrangeiras. O sistema universitário nacional não dispunha ainda da capacidade para produzir conhecimento antropológico certificado. Neste sentido, os jovens antropólogos nativos mencionados devem ser considerados como estrangeirados. ${ }^{7}$ Não se sabia o futuro que poderiam ter.

\section{ANTROPÓLOGOS EM ÁREAS PROTEGIDAS}

A atividade de campo empreendida pelos antropólogos, folcloristas e etnomusicólogos referidos caracterizou-se por se tratar de iniciativas individuais tendo em vista a elaboração de teses académicas. Inseriram-se em pressupostos discutidos em contextos académicos outros que não os portugueses.

Constitui exceção ao quadro traçado a pesquisa levada a cabo por Manuel Viegas Guerreiro (1912-1997), professor de etnologia no curso de Geografia da Universidade de Lisboa. Dando seguimento a um pedido feito pela instância governamental responsável pelo Parque Nacional da Peneda-Gerês (criado em 1971, no Alto Minho), fez trabalho de campo durante quase um ano em 1977-78. Escolheu a aldeia de Pitões das Júnias com um duplo intuito: estudar a já clássica questão do comunitarismo agropastoril na etnografia portuguesa e verificar como melhorar o relacionamento da população aldeã com a direção do parque. O projeto inicial previa uma participação mais intensa e regular de uma equipa de antropólogos na produção de conhecimento aplicável à gestão daquela primeira área protegida portuguesa. Um grupo emergente de antro-

6 Ver < http://cpdoc.fgv.br/cientistassociais/joaopina $>$, 7. ${ }^{\circ}$ bloco (última consulta em maio de 2014). Posteriormente escreveu sobre a sua experiência (Pina-Cabral 1992).

7 Faço uma listagem das obras que resultaram das pesquisas de terreno referidas, quase todas publicadas (e/ou traduzidas) a partir de doutoramentos; o seu impacto só se verificaria a partir da década seguinte, já como leitura disponível para os estudantes: Branco (1987 [1984]); Brito (1996); Pina-Cabral (1986); Caufriez (1998a, 1998b); Espírito Santo (1980); Guerreiro (1981); O’Neill (1984); Piselli (1996); Purcell (2002). 
pólogos da Universidade do Minho, integrando, entre outros, Alice Duarte Geraldes (1923-) e Luís Polanah (1921-2005), associou-se a esta antropologia implicada no parque, daí resultando algumas publicações preliminares. A monografia de Manuel Viegas Guerreiro sobre a mencionada aldeia de montanha Pitões das Júnias seria publicada em livro no início da década de 1980 (Guerreiro 1981). Para além da monografia, foi conselheiro do documentário em longa-metragem realizado por Ricardo Costa e intitulado Pitões, Aldeia do Barroso (1979, 16 mm, cor, 86', Diafilme/RTP).

A delimitação de áreas protegidas foi campo onde as autoridades nestes anos 70 tentaram envolver cientistas sociais, mostrando-se sensíveis à abordagem antropológica. Refira-se a ação de Alberto Martinho (1947-) no Parque Natural da Serra da Estrela. Era um antropólogo nativo (Martinho 1972) e residente na região e, nessa qualidade, contratado pela administração do parque. Dessa experiência publicou - entre outros assuntos - sobre a produção de queijo (Martinho 1980).

A elaboração de estudos antropológicos resultantes de encomendas feitas por organismos governamentais não singrou. As razões deverão ser procuradas em dois planos. Primeiro, a incapacidade desses organismos em assegurar o financiamento continuado de pesquisas. Segundo, a inabilidade da antropologia em processo de institucionalização académica para se articular com ações práticas fora da universidade (contratos, prazos, recursos humanos, gestão). ${ }^{8}$

\section{CONCLUSÕES}

Uma série de acontecimentos (exposição da AICA no museu, ciclo Jean Rouch, estreia duma etnoficção, publicação da obra terminal do atlas etnográfico) e alguns processos iniciados (questão do museu por solucionar, licenciatura em antropologia criada de raiz, pesquisas de terreno individuais em andamento orientadas em universidades estrangeiras, tentativa de pesquisa antropológica aplicada em equipa sem continuidade), eis o quadro traçado para a década em análise.

8 Merecem referência pessoas que, em posições de decisão mais destacadas ou menos visíveis, defenderam uma investigação antropológica aplicada. Para que viesse a participar uma equipa composta por antropólogos da Universidade do Minho e ainda por Manuel Viegas Guerreiro, da de Lisboa, na pesquisa a empreender no Parque Nacional da Peneda-Gerês, devem ser lembrados os esforços de M. Gomes Guerreiro, professor de silvicultura da Universidade Técnica de Lisboa, quando foi secretário de Estado do Ambiente (1976) e encomendou o projeto, bem como de A. Lima de Carvalho (1928-2006), professor de antropologia na referida Universidade do Minho. Este último seria mais tarde nomeado diretor do Museu de Etnologia, incumbindo-lhe a tarefa de preparar e concretizar a abertura ao público do museu, o que aconteceu em 1985. Relativamente ao Parque Natural da Serra da Estrela e ao ex-Serviço Nacional de Parques e Reservas Naturais (atual Instituto da Conservação da Natureza) menciono o seu primeiro diretor, o engenheiro paisagista Fernando Pessoa. Não só defendeu a participação, como contratou antropólogos, provavelmente porque é um admirador de Georges-Henri Rivière. 
Da conjugação destes elementos ressalta uma situação caracterizada por rutura e arranque, mas não de renovação. Vista noutros termos, a antropologia desses anos não é de construção da nação, não a evoca na sua essência, antes busca o país numa indagação ora contemplativa, ora inconformada (ecos da revolução e da descolonização). Também não é ainda internacional, porque embora o terreno esteja a ser visitado, as etnografias elaboradas resultam de ações individuais e serão formatadas no exterior. Colocada a questão nestes termos, a proposta de Stocking (1982) não permite atribuir sentidos aos dados expostos. Aqui pretendi aprofundar a análise dum processo de descontinuidade num quadro de produção nacional, alargando a dimensão temporal ao contexto vivido nos anos 1970, em que a revolução do 25 de Abril é determinante (Branco 2010).

O contexto então vivido pauta-se pelas ondas de choque geradas pela emancipação colonial. A ainda insipiente comunidade antropológica portuguesa retira-se numa atitude de luto intelectual: abstinência forçada em relação a África, contenção em casa. Se se procurarem paralelos, será na França face à Argélia colonial, onde existiu situação comparável: colonialismo, antropologia praticada para dominar o colonizado, guerra de libertação, descolonização, êxodo de colonos, recriminações prolongadas.

E o luto gerou uma dinâmica revitalizadora. A geração emergente de antropólogos (os jovens docentes regressados do estrangeiro e os estudantes) não se reconhece no paradigma científico herdado e altera os seus termos: a busca de harmonia vigente no passado (igualitarismo) cede lugar à ênfase posta no conflito (desigualdade).

\section{BIBLIOGRAFIA}

ALMEIDA, Sónia Vespeira de, 2009, Camponeses, Cultura e Revolução: Campanhas de Dinamização Cultural e Acção Cívica do MFA (1974-1975). Lisboa, Edições Colibri.

BRANCO, Jorge Freitas, 1987 [1984], Camponeses da Madeira: As Bases Materiais do Quotidiano no Arquipélago, 1750-1900, Lisboa, Dom Quixote (original em alemão: Bauernarbeit im mediterranen Alltag: Agrikultur und Umweltgestaltung auf der Inselgruppe Madeira, 1750 -1900, Berlim, Reimer Verlag).

BRANCO, Jorge Freitas, 1989, "Entre a imagem e a realidade: reflexões sobre a Madeira como experiência antropológica”, em Actas do I Colóquio Internacional de História da Madeira. Funchal, Governo Regional da Madeira, vol. 1, 270-306, disponível em < https://repositorio.iscte.pt/handle/10071/1179> (última consulta em maio de 2014). 
BRANCO, Jorge Freitas, 2010, “Wie die Feldforschung übernommen wurde: Über periphere Beziehungen in der Ethnologie”, em Nils Grosch e Sabine Zinn-Thomas (orgs.), Fremdheit Migration Musik: Kulturwissenschaftliche Essays für Max Matter. Münster, Waxmann Verlag, 169-184.

BrAnCO, Jorge F., e Luísa T. de OliveIRA, 1993, Ao Encontro do Povo. I: A Missão. Oeiras, Celta Editora.

BRetell, Caroline, 1978, Hope and Nostalgia: The Migration of Portuguese Women to Paris. Providence, Universidade de Brown, tese de doutoramento.

BRITO, Joaquim Pais de, 1996, Retrato de Aldeia com Espelho: Ensaio sobre Rio de Onor. Lisboa, Publicações Dom Quixote.

CALLIER-BOISVERT, Colette, 1999, Soajo: Entre migrations et mémoire. Etudes sur une société agro-pastorale à l'identité rénovée. Paris, Centre Culturel Calouste Gulbenkian.

CAUFRIEZ, Anne, 1998a, Le chant du pain: Trás-os-Montes, recherches sur le Romanceiro. Paris, Centre Culturel Calouste Gulbenkian.

CAUfrieZ, Anne, 1998b, Romances du Trás-os-Montes: Mélodies et poésies. Paris, Centre Culturel Calouste Gulbenkian.

CORDEIRO, Graça I., e Ana I. AFONSO, 2003, "Cultural and social anthropology in the Portuguese university: dilemmas of teaching and practice”, em Dorle Dracklé, Iain Edgar e Thomas K. Schippers (orgs.), Educational Histories of European Social Anthropology. Oxford, Berghahn Books, 169-180.

CPR, 1976, Ciclo Jean Rouch, catálogo. Lisboa, Cooperativa Paz dos Reis.

CUTILEIro, José, 197 1, A Portuguese Rural Society. Oxford, Clarendon Press (versão em português: Ricos e Pobres no Alentejo, Lisboa, Sá da Costa, 1977; 2. ${ }^{a}$ edição: Livros Horizonte, 2004).

DAVIS, John, 1977, People of the Mediterranean: An Essay in Comparative Social Anthropology. Londres, Routledge and Kegan Paul.

ESPÍRITO SANTO, Moisés, 1980, Comunidade Rural ao Norte do Tejo: Estudo de Sociologia Rural. Lisboa, Instituto de Estudos para o Desenvolvimento.

GALlo, Donato, 1988, Antropologia e Colonialismo: O Saber Português. Lisboa, ER Heptágno. GOUVEIA, Henrique Coutinho, 2009, Museu Etnográfico da Madeira: Estudo de Um Modelo de Avaliação. Praia, Universidade de Cabo Verde / Tomar, Instituto Politécnico de Tomar.

GUERreIro, Manuel Viegas, 1981, Pitões das Júnias: Esboço de Monografia Etnográfica. Lisboa, Serviço Nacional de Parques, Reservas e Património Paisagístico.

LAWRENCE, Denise, 1979, Festa: Cooperation in Rural Southern Portugal. University of California Riverside, tese de doutoramento.

LIMA, A. Mesquitela, 1976, "Apontamentos sobre escultura negro-africana: a propósito de uma reunião da AICA e de uma exposição", Colóquio Artes, 2. ${ }^{a}$ série, 30: 41-49.

MARTINHO, Alberto, 1972, Sabugueiro. Lisboa, ISCSPU.

MARTINHO, Alberto, 1980, O Queijo da Serra: Subsídios para a Sua Demarcação. Coimbra, Almedina.

MATOS, António Perestrelo de, 1999, “Museu Etnográfico da Madeira”, em Nélia Dias (org.), Roteiro de Museus: Coleções Etnográficas, vol. 5: Açores e Madeira. Lisboa, Olhapim.

ME, 1979, Decreto n. ${ }^{\circ}$ 128-A/79, de 23 de novembro, Ministério da Educação, disponível em < http://dre.pt/pdflsdip/1979/1 1/27101/00010002.pdf > (última consulta em maio de 2014). 
MEIC, 1978, Decreto regulamentar n. ${ }^{\circ}$ 1/78, 10 de janeiro, Ministério da Educação e Investigação Científica, disponível em < http://dre.pt/pdflsdip/1978/01/00800/00650066. pdf $>$ (última consulta em maio de 2014).

O’NEILl, Brian J., 1984, Proprietários, Lavradores e Jornaleiras: Desigualdade Social Numa Aldeia Transmontana (1870-1978). Lisboa, Publicações Dom Quixote (versão em inglês: Social Inequality in a Portuguese Hamlet: Land, Late Marriage, and Bastardy, 1870-1978, Cambridge, Cambridge University Press, 1987).

OLIVEIRA, Ernesto Veiga de, 1968, Vinte Anos de Investigação Etnológica do Centro de Estudos de Etnologia Peninsular: Porto 1947 - Lisboa 1967. Lisboa, Instituto de Alta Cultura.

OliveirA, Ernesto Veiga de, Fernando GALHANO, e Benjamim PEREIRA, 1976, Alfaia Agrícola Portuguesa. Lisboa, Instituto de Alta Cultura.

OliveirA, Luísa T. de, 2004, Estudantes e Povo na Revolução: O Serviço Cívico Estudantil (1974-1977). Oeiras, Celta Editora.

PEREIRA, Maria Manuela Cantinho, 2005, O Museu Etnográfico da Sociedade de Geografia de Lisboa: Modernidade, Colonização e Alteridade. Lisboa, Fundação para a Ciência e a Tecnologia/Fundação Calouste Gulbenkian.

PEREIRA, Rui, 2006, Conhecer para Dominar: O Desenvolvimento do Conhecimento Antropológico na Política Colonial Portuguesa em Moçambique, 1926-1959. Lisboa, Faculdade de Ciências Sociais e Humanas da Universidade Nova de Lisboa, tese de doutoramento em antropologia.

PINA-CABRAL, João de, 1986, Sons of Adam, Daughters of Eve: The Peasant Worldview of the Alto Minho. Oxford, Clarendon Press (versão em português: Filhos de Adão, Filhas de Eva: A Visão do Mundo Camponesa no Alto Minho. Lisboa, Publicações Dom Quixote, 1989).

PINA-CABRAL, João de, 1992, Aromas de Urze e de Lama: Viagens de Um Antropólogo ao Alto Minho. Lisboa, Editora Fragmentos.

PISELLI, Fortunata,1996, Caminhos Silenciosos da Mudança (Quatro Aldeias antes e depois do 25 de Abril). Lisboa, FCG e JNICT.

PITT-RIVERS, J.A., 1954, The People of the Sierra. Nova Iorque, Criterion Books.

PURCELl, Joanne B., 2002, Romanceiro Tradicional das Ilhas dos Açores. Angra do Heroísmo, Governo Regional dos Açores.

ROCHA-TRINDADE, Maria Beatriz, 1970, Immigrés portugais: Observation psycho-pociologique d'un groupe de Portugais dans la banlieue parisienne (Orsay). Paris, Sorbonne, tese de doutoramento.

SEC, 1976, Modernismo e Arte Negro-Africana: Exposição no Museu de Etnologia. Lisboa, Secretaria de Estado da Cultura.

SOUSA, Ernesto de, 1976, "O Congresso da Associação Internacional de Críticos de Arte (AICA) em Portugal”, Colóquio Artes, 2. ${ }^{\text {a }}$ série, 29: 56-57.

STOCKING, George W., 1982, "Afterword: a view from the Center", Ethnos, 47 (1-2): 172$-186$.

WEST, Harry, 2004, "Inverting the camel's hump: Jorge Dias, his wife, their interpreter, and I", in R. Handler (org.), Significant Others: Interpersonal and Professional Commitments in Anthropology. Madison, The University of Wisconsin Press, 51-90. 